Matabane, B. R. \& Matabane, M. E. Black Students' Experiences of Academic

Support Programs during First Year at University: Case of Extended Studies

\title{
Black Students' Experiences of Academic Support Programs during First Year at University: Case of Extended Studies
}

\author{
Belinda Ramathetse Matabane ${ }^{1}$ \& Mogalatjane Edward Matabane ${ }^{* 1}$ \\ *Corresponding Author: Edward.Matabane@spu.ac.za \\ 1. Sol Plaatje University, Northern Cape, South Africa \\ Received : 2021-06-28 \\ Revised : 2021-07-30 \\ Accepted : 2021-08-25 \\ $10.46303 /$ ressat.2021.28
}

\begin{abstract}
How to cite this paper: Matabane, B. R. \& Matabane, M. E. (2021). Black Students' Experiences of Academic Support Programs during First Year at University: Case of Extended Studies. Research in Social Sciences and Technology, 6(3), 93-108.

https://doi.org/10.46303/ressat.2021.28
\end{abstract}

This is an Open Access article distributed under the terms of the Creative Commons Attribution 4.0 International license (https://creativecommons.org/licenses/by/4.0/).

\begin{abstract}
In the last three decades, historically white, liberal arts universities began to admit small numbers of black students from rural communities because apartheid policies relaxed. However, those liberal arts universities had doubts about black students' key skills and knowledge to cope with the demands of higher education. This situation gave birth to Extended Studies Program (ESP) whereby the traditional three-year degree program was extended by a year to close this gap. This study seeks to answer the question: What are black students' experiences and views about academic support offered to them during their first year at university? In this study both qualitative and quantitative research methods were followed, and purposive sampling was deployed. Data were generated from different sources for triangulation, namely questionnaires and interviews. Participants $(N=104)$ were made of 43 males and 61 females. The results of the study suggest that the need for academic support is not exclusive to first-year students. Improved systematic academic support gives rise to improved student academic performance. Throughout the study, necessity, and urgency of Academic Support Programs (ASPs) is recognized. Recommendations are made suggesting that ASPs be administered throughout the undergraduate programs and not just at the first-year level of study.
\end{abstract}

Keywords: Academic support; academic support programs; extended studies programs; experiences. 
Matabane, B. R. \& Matabane, M. E. Black Students' Experiences of Academic Support Programs during First Year at University: Case of Extended Studies

\section{Introduction}

Post-apartheid South Africa promised democratization and de-racialization of access to higher education. However, the extent to which the country has lived up to these standards remains questionable. The majority of South Africans continue to bear the brunt of apartheid legacy concerning education. Despite the notable reforms since 1994, it is evident that access to quality education is still differentiated across racial and class lines. With persisting inequalities, schools that serve mostly black students inadequately prepare them for post-secondary education. As a result, there are major challenges for higher education institutions as they are expected to cater to 'under-prepared' students. Academic Support Programs (ASPs) can bridge this gap. Thus, there is an urgent need of these programs.

The need for ASPs in higher education is widely acknowledged (Bitzer, 2003; Boughey, 2010; Council on Higher Education [CHE], 2013; Jones et al., 2008; Junio-Sabio, 2012; Letseka et al., 2009). Academic support is seen as part of the ongoing debate about meeting the students' varying academic and non-academic needs. However, Boughey (2013), contend that "even after apartheid, the 'revolving door' syndrome of high drop-out and failure rates continued to be a feature of the higher education system in general, and for Africans in particular" (p. 18). Despite an increase in the number of students enrolling in higher education, success in terms of throughput and graduation rates has continued to favor certain racial groups, and whites (Scott et al., 2007; Smolikevych, 2021).

Although physical access may have improved for those in previously excluded racial groups, epistemological access, and success for many has remained elusive. The provision of access to higher education has been increased by admitting African students in the white liberal arts universities through extended studies programs (ESPs). The history of ESPs has been marked by an attempt to 'fix' students' problems. As such, these attempts are not sufficient to better suit the needs of the 'ill-prepared' students; this issue has been at the forefront of many institutions. The aim has been to make students fit in the already existing institution as opposed to radically transforming the institutions themselves. In this study, we explore the students' experiences and views of ASPs offered during their first year in the extended studies program at a South African university.

\section{Objective of the Study}

The central goal of this paper is to explore students' experiences and views of ASPs in higher education. This study is conducted against the backdrop of the transformation agenda in higher education in post-apartheid South Africa. Post-apartheid, access to higher education was expanded with little preparedness. As a result, the articulation gap between school and university, institutional culture, unpreparedness of universities and underpreparedness of students widened (Bitzer, 2009; Boughey, 2010; Boughey \& McKenna, 2016; Maphosa, 2014; Nel et al., 2009; Ramapela, 2012; Spaull, 2013). The arguments, largely, revolve around deficit assumptions "constructing students as lacking skills, experiencing gaps in conceptual knowledge areas, in need of language development and lacking the ability to think critically" (Boughey, 2010, p. 5). Equally important, the study is informed by the perennial problem of attrition, retention, and throughput (Spaull, 2013; Weuffen et al., 2021). 
Matabane, B. R. \& Matabane, M. E. Black Students' Experiences of Academic Support Programs during First Year at University: Case of Extended Studies

\section{Research Questions}

The primary question for the study is: "What are black students' experiences and views about academic support offered to them during their first year at university?"

Emanating from the study primary question, the study seeks to respond following subquestions:

- What are students' views on the need for academic support during first year at university?

- How do students feel about entering university through ESP?

- What can be improved in ESP to improve success rate of students?

\section{Literature Review}

This section explains the foundational understanding of the birth of ESPs in South African higher education and how different institutions in South Africa implement ESP within their context.

\section{Understanding Extended Studies Programs (ESP) in Higher Education}

Historically, South African universities designed ESPs to provide access to higher education for prospective students from previously racially divided and disadvantaged educational backgrounds (Boughey \& McKenna, 2016; Department of Education [DoE], 2001). Department of Higher Education and Training (DHET) in South Africa explained that the purpose of the providing extended studies is to create an academic pathway for the under-prepared cohort of students entering higher education (DHET, 2012).

Thus, the state has funded Extended Studies Programs (ESPs) since 2004 to "address systemic inequities in the higher education sector in South Africa" (Bangeni \& Kapp, 2017, p. 6). The ESP is structured in a way that the traditional three-year degree programs are stretched over four years; the focus of the first year is to align courses with the student's educational backgrounds and needs. The stretching of three-year programs to four years allows slower pacing of teaching, giving students more support as the normal first year in the main is taught over two years for students in the ESP.

Extended Studies Programs (ESPs) are said to target students who do not meet the minimum requirements (DHET, 2016), and lack the necessary competencies to succeed in their studies. These programs consist of almost always black students. Central line of argument is that successful support programs require a confluence of academic, social, and personal and other non-academic factors (Boughey \& McKenna, 2016; Ntakana, 2011). The commitment to academic support is according to Bitzer (CHE, 2016) "a major contribution of higher education institutions towards benefitting societies, their potential to assist students in their academic progress as well as their progress in other spheres" (p. 60)

Academic Support (AS) occurs within the broader field of Academic Development (AD). AD is defined by the Higher Education Quality Committee (HEQC) (CHE, 2007) as:

A field of research and practice that aims to enhance the quality and effectiveness of teaching and learning in higher education and to enable institutions and the higher 
Matabane, B. R. \& Matabane, M. E. Black Students' Experiences of Academic Support Programs during First Year at University: Case of Extended Studies

education system to meet key educational goals, particularly in relation to equity of access and outcomes. (p.74)

Academic support definitions vary in emphasis. Broadly, AS is founded on the principle of fostering the development of students' competencies, life skills and habits of academic excellence (Junio-Sabio, 2012). Generally, definitions stress the transformational potential of AS and the provision of equal learning opportunities in a structured and controlled top-down professional setting (Ramapela, 2012). These definitions of AS tend to eliminate the active role that students play in their own learning and are viewed as passive recipients.

Needs-based and target-oriented definitions, especially those grounded in the deficit skills/learning argument, define AS, "the purposeful shaping of the instructional process to address the learning needs of students in particular teaching contexts" (Warren, 1998, p. 76) and as a "planned response toward an identified need for action" (Rhodes University, 2012, p. 5). With this definition, AS interventions enable students from disadvantaged socio-economic and educational backgrounds to develop their literacy and study skills (Smith, 2009). In contrast, Warren (1998) provides a comprehensive definition and views AS as an integrated intervention targeting ALL students. This definition is based on the recognition that "learning in higher education is a complex social and cognitive process of discovering and internalizing which cannot be dealt with in a remedial fashion but constitutes the very means through which academic learning and knowledge construction occurs" (Warren, 1998, p. 77).

Such a conceptualization by Warren (1998) underpins this study. It concurs with Tanyanyiwa's (2014) observation that "under-preparedness is not peculiar to extended studies students but is widespread across the student body" (p. 261). This view is echoed by Spaull (2013) that "academic difficulties which stem from the impoverished school education are not exclusively experienced by black students" (p. 10).

Research trends on AS in South Africa overlap with international scholarship especially on atrisk, under-prepared students or under-represented minorities, first-generation students, retention, and attrition rates, teaching and learning approaches, and study of academic and non-academic factors that influence success or failure (Bitzer, 2009; Boughey, 2010; Jones et al., 2008; Letseka et al., 2009; Nel et al., 2009; Ramapela, 2012). There is consensus that the first year of study is the most critical for student learning, adjustment and overall development and should be targeted to prevent early attrition and non-completion. Research highlights increasing participation and diversification of a student body that is ill-prepared for the demands of higher education. It is particularly so for first-generation students. In South Africa, the racial discourse, and the articulation gap ${ }^{1}$ dominates the debates. A study by Lowe and Cook (2003) of first year students at the University of Ulster confirms the findings of van Schalkwyk (2007) and Nel et al. (2009), that there is a difficulty in bridging the school-university gap. 
Matabane, B. R. \& Matabane, M. E. Black Students' Experiences of Academic Support Programs during First Year at University: Case of Extended Studies

\section{Higher Education Institutions Implementation of ESP: A Case of Four Universities in South Africa}

The establishment of ASPs at University A, in the Eastern Cape province in 1982, was a result of several years of deliberation "brought about by the plight of academically 'at risk' students at the university" (Drewett, 1993, p. 72). The aim was to "improve the quality and quantity of graduates who belong to the so-called Black, Colored and Indian groups" (Drewet, 1993, p. 75).

Post-1994, University A expanded their ASP by introducing the Extended Studies Program (ESP). The ESP is considered "a vital part of the university's goal of widening access to include learners from a more diverse range of educational, cultural and socio-economic backgrounds, whose disadvantaged backgrounds may have hindered their school leaving performance" (Boughey, 2013 , p. 12). ESPs are also conceptualized as "initiatives aimed at expanding the institutional culture through inclusive practices that are supportive of a diverse student body" (Boughey, 2013 , p. 8). The Audit Report on University A, (HEQC, 2007:51), noted that, only about 30\% of enrolments at the institution were black South African students. When the Extended Studies Unit (ESU) was established, it was understood that its role in the university was related to the need to increase enrolments of black students.

At University B, also in the Eastern Cape, a similar program, Extended Degree Program (EDP) was introduced to "assist students with proven potential but without adequate schooling in mastering the skills required to complete their chosen degrees" (van Schalkwyk, 2007, p. 14). Like University A, EDP added a fourth year to a mainstream three-year degree program to form an EDP. The students in EDP received much support, and the one semester course was taught over a year to devote sufficient time on preparing students for demands in the mainstream.

At University $C$, in Free State province, a similar program was developed called extended curriculum/foundational provision. The students are admitted to this extended curriculum by looking at the previous results from schools and classify the students as at risk of failure due to their educational background. What makes University $C$ interesting is that students could be admitted to foundational programs even if they met the minimum admission points to be in the mainstream. Thus, the focus here is not to give students access but to "enable success by providing academic foundations for successfully completing their studies" (DHET, 2012).

At University D, in the Western Cape province, their support programs are targeted at students from historically and currently disadvantaged educational backgrounds. Their focus is to enable students to adapt to the tertiary education environment and culture that might be foreign to their lived experiences (Spaull, 2015, Valenzuela et al., 2021).

\section{Conceptual Framework}

Given the complexity of issues which academic support seeks to address, studies on higher education have spanned both conceptual and pragmatic issues. This study adopts a twopronged approach to the conceptual framework. First, the seminal academic and social integration model by Tinto $(1993,1997)$ is instructive. It puts emphasis on the "successful integration into the academic and social structures of the institution" (Strauss \& Volkwein, 2004, p. 24). The model not only explains factors determining students' early departure but also provides valuable insights into academic success. "The model assists in the interpretation of data gathered on student attributes but also clarifies students' goals and commitment" (Bitzer, 
Matabane, B. R. \& Matabane, M. E. Black Students' Experiences of Academic

Support Programs during First Year at University: Case of Extended Studies

2009, p. 164). Modified by Louw (2005), this model has been used as an interpretive and holistic framework for first-year student support and development at institutions of higher learning (Bitzer, 2009). Louw's academic risk indicators (study goals, student perceptions of higher education, skills and knowledge gaps, academic adjustment, program choices, language difficulties, course and learning materials and access granted to students who did not meet the required access requirements) provide a useful entry point for this study.

Secondly, the study draws on the voluminous literature on the nature of learning in higher education (Bitzer, 2009; Boughey, 2010; Boughey \& McKenna, 2016; Dison \& Pinto, 2000; Maphosa, 2014; Mwangi \& Yao, 2021; Spaull, 2013). Of importance are the students' conceptions of learning and teaching. Student learning is understood as a complex multivariate phenomenon, with students exhibiting qualitatively different levels of understanding of what they have learned (Maphosa, 2014; Patimo \& Lucero, 2021). There is evidence that a correlation between the various approaches to learning and academic success exists, hence it is necessary to understand the nature of academic support that exists to determine what is needed. Both conceptual frameworks adopted in this study provide the platform for studying the wider academic context within which students find themselves: socially, institutionally, and academically.

\section{Methodology}

\section{Research design}

This study used mixed method research. Researchers in this study collected, analyzed and integrated both quantitative and qualitative data into one study to avoid biases inherent in single method of data collection. The study adopted a case study design of one university situated in the Eastern Cape, South Africa. According to Creswell (2014), qualitative approach to a case study allows the researcher to focus on one or more cases over time through detailed, in-depth data collection involving multiple sources of information. The use of multiple sources of information results in triangulation which contributes to the validity of an investigators research. In this study, we aimed to provide in-depth understanding through data analysis of multiple sources of information describing all details of the case by identifying themes or issues (Creswell, 2014).

\section{Population and sample}

According to Khan (2014) you cannot study everyone everywhere doing everything. This then makes sampling crucial in research (van Rijnsoever, 2017). The participants were former extended studies program students who are now in the second year of studies in the mainstream at a university located in Eastern Cape. The university was purposefully selected because it is generally believed to have best resources to give great support to ESP students. A convenient sampling technique was used to select 126 second year level students who just completed their year in ESP and could easily be reached. A sample of 108 students (Table 1) participated in the study. Descriptive statistics (frequency and percentage) were used to analyze the data from Likert scale type of questions while thematic analysis was (Rowley, 2014) was used to analyze data from questionnaires. 
Matabane, B. R. \& Matabane, M. E. Black Students' Experiences of Academic Support Programs during First Year at University: Case of Extended Studies

Table 1. Demographic Profile of students

\begin{tabular}{lll}
\hline Variables & Frequency & Percentage \\
\hline Gender & & \\
\hline Male & 43 & 39.9 \\
Female & 61 & 56.4 \\
Not indicated & 4 & 3.7 \\
\hline Age & & \\
\hline $18-25$ & 93 & 86 \\
$26-33$ & 15 & 14 \\
Total & 108 & 100.0 \\
\hline
\end{tabular}

\section{Data Collection instruments}

Data were collected using questionnaires and interviews.

\section{Questionnaires}

Questionnaires were of importance to reach several students and gain insight on a given phenomenon (Moerdyk, 2009). Data collected through questionnaires is also easy to be quantified either by the researcher or the use of software package (Rowley, 2014). The questionnaire comprised of 25 items (Appendix A). The items were divided into four sections. Section A had three items about the demographic data (gender, age, race) of the students. Section B consisted of four items that dealt with experiences of coming to university. Section C focused on support given at ESU and consisted of 13 items and Section D dealt with students' views of academic support and had five items. In Section D, the students were expected to express their level of agreement, or otherwise on a four-point Likert scale (agree, strongly agree, disagree, strongly disagree).

The reliability of the instruments, namely internal consistency, was established using Cronbach alpha. A value of 0.912 was obtained, meaning that the instruments could be judged reliable.

\section{Interview}

Interviews were used to gain insights into participants' experiences and perceptions as well as interpretations which the researcher would not otherwise obtain through mere questionnaires (Moerdyk, 2009). The interviews were scheduled for 45 minutes to one hour for participant. The researchers recorded the interview, using a voice recorder. The recording captured the interview, and they were transcribed verbatim soon after the interview concluded. These transcriptions were returned to interviewees for member checking.

In collecting data, participants were told from the beginning that although they agreed to be part of the study, they could withdraw at any stage and were not obliged to answer all the questions. They were also ensured anonymity and confidentiality. To assure participants of 
Matabane, B. R. \& Matabane, M. E. Black Students' Experiences of Academic Support Programs during First Year at University: Case of Extended Studies

anonymity and confidentiality, a consent form was issued stipulating what they were entitled to for the duration of the study and after. Only pseudonyms are used in reporting the finding if this study. The study received ethics clearance from the University A where the data was collected.

\section{Data analysis}

The data was analyzed in a manner that reveals relationships, patterns and trends that could possibly be found within it. We compared our information to other people's work, in this case the literature review so that conclusions could be drawn. All qualitative data was coded to examine common themes and patterns (Creswell, 2014). Descriptive statistics and content analysis were used to analyze quantitative and qualitative data respectively.

\section{Results and Discussion}

The findings of this study are discussed using the order of the research questions. In responding to the question on the need for academic support during first year, eighty-two (76\%) of the respondents strongly agree that there is a need for academic support during first year of study, eighteen (17\%) agree, six (5.65) disagree, and 2 (1.85\%) strongly disagree. Thus, the necessity and urgency of ASPs is recognized. Respondents strongly hold the view that the reason they all need academic support is because they come from different backgrounds and different schools in different areas. Thus, as put by participant Lindokuhle:

[...] we had different academic experiences so definitely that is very important, and I am assuming that is why the institution had the Extended Studies Program (ESP) in the first place, but even with the mainstream undergraduates, there is a dire need of support because there is no lie that one does get overwhelmed by university studies.

This view is also shared by Esihle when she said, "University is like a complete different world, I felt lost and could not do without support".

Students struggle to get the being of academic literacy (Ellery, 2016). They have 'known' in one way all their lives (typically as recipients of accepted facts). They have been successful knowers in the past and suddenly they start to fail because they must become different kinds of knowers. Therefore, certain ways of knowing are being legitimized and different from what students knew as knowledge and support programs can assist in breaking this code (Maton, 2014).

Responding to the second research question, students have varied perceptions about entering university through ESP and its relevance. When asking a former Extended Studies (ES) student about her perception of ESP and the academic support programs, she noted that during her first year, she felt like she lost a year. However, she asserted that after being in the ESP program, she started realizing just how important and beneficial it was: as she puts it:

Extended Studies helped you know, it helped because I was never exposed to library, I did not even know how that works, we did not have a library at school, secondly, just extra support from lecturers in the ES classes, knowing that I will go to mainstream class and if do not understand anything, in class again it will be repeated in ES that was nice and even that thing of small groups it helps. (Siphosenkosi) 
Matabane, B. R. \& Matabane, M. E. Black Students' Experiences of Academic Support Programs during First Year at University: Case of Extended Studies

Another former Extended Studies student shared this view by noting that he would have struggled throughout first year without the support provided in ES. As he puts it:

$[\ldots]$ the fact that we were not exposed to computers in my school, ES helped me a lot, we had computer literacy, the lecturers and tutors were friendly, approachable supportive [...]. (Lethabo)

This student strongly holds that the kind of school he went to did not offer him many opportunities, so if it were not for the Extended Studies Program, he would not have survived. This student went to a public, under-resourced school which he felt had a negative impact on his high school performance.

Adding to this, Dimpho says:

To be honest, I was very sad when I was told I will do a three-year degree in four years while others do it in three years, now I understand why, I think even if I passed matric exam well, given opportunity I will choose ES over mainstream, it is worth it, my smart friend FAILED first year of mainstream although they brag of being smart.

Studies have shown that successful support programs require a confluence of academic, social, and personal and other non-academic factors (Maphosa, 2014; Tinto, 1997; Ntakana, 2011; Wong et al., 2005). This view was shared by the respondents. According to these respondents, support should go beyond studies. They argued that university was not what they expected. Apart from being a new experience, they felt left out and thrown into very deep water without a lifejacket of guidance and support in other spheres of life. This ties with Tinto's $(1993,1997$, 2003) and Yorke and Thomas (2003) argument that the transition from secondary to tertiary is a challenging one. In South Africa, the racial discourse and the articulation gap dominate the debates. A study by Lowe and Cook (2003) of first year students at the University of Ulster confirms the findings of van Schalkwyk (2007) and Nel et al. (2009), of the difficulty in bridging the school-university gap.

Regarding improvement of the academic support offered, respondents generally held the view that academic support should target every student and be offered throughout their undergraduate studies. Figure 1 below, shows that from 108 participants, 72 (67\%) of the respondents hold the view that academic support should not only target first year students but be offered throughout the undergraduate programs. "[...] though research on student attrition is plentiful and debate over theories of student persistence vigorous, less attention has been paid to the development of a model of institutional action that provides institutions for effective action to increase student persistence and in turn student success" (Tinto \& Pusser 2006 , p. 4). Although, access to higher education has become an acceptable indicator of a nation's development, the offering of academic throughout undergraduate might address more than just access but success rates of students. 


\section{LEVEL WHERE SUPPORT IS NEEDED}

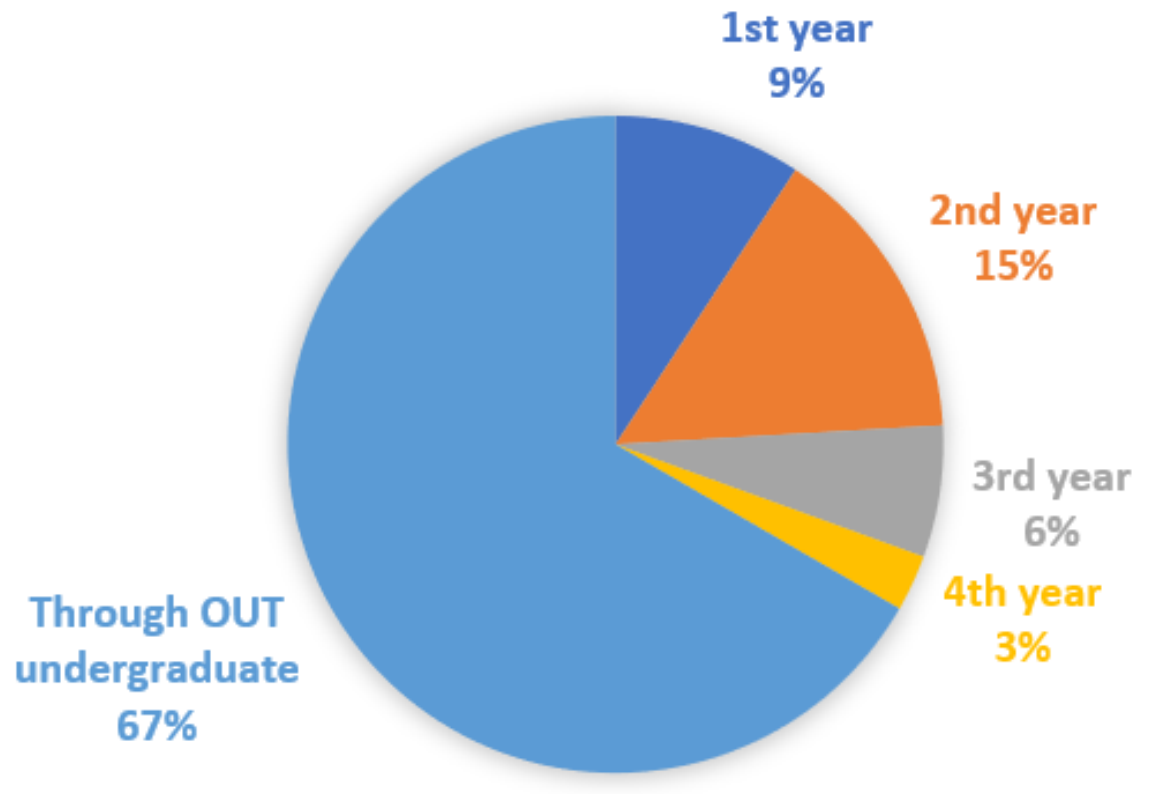

Figure 1. Pie chart showing distribution of level of study where Academic Support is required.

Thus, as put by Bongiwe:

[...] academic support should be offered to all students, it does not matter which year of study, university is not easy, each year of study has its own challenges, we all need that support.

Sebutsi noted:

[...] you know it would have been nice if the university can have some sort of way to assist us in our emotional wellbeing, you know there are things that we struggle with, somewhere where you can have someone to talk to.

It can be argued that higher education institutions have a responsibility to look at students holistically, instead of detaching the mind from the whole being. For some students, the challenge is trying to fit in the university culture, which then impacts their studies. Relating to Tinto's (1993) student integration model, students can leave school due to lack of integration in the institution they form part of university culture needs to be welcoming and considerate of all students if they are to make the most of their studies.

\section{Study Limitation}

This study has limitations. Firstly, the data was collected from only second year students. Therefore, the voices of students who went through ESP but are in their third or fourth year are missing. The data is also from only students who were in ESP. Voices of learners in the 
Matabane, B. R. \& Matabane, M. E. Black Students' Experiences of Academic Support Programs during First Year at University: Case of Extended Studies

mainstream are missing. Again, since the ESP was mainly black students, the voices of other races are missing.

\section{Conclusion and Recommendations}

The transformation agenda in higher education in post-apartheid South Africa in terms of expanding access to education, the promotion of accountability and efficiency in higher education, massification, the articulation gap between school and university, institutional culture, unpreparedness of universities and under preparedness of students comprise the conceptual core of this study. In analyzing the overall findings, respondents hold distinct yet similar views on the need for ASPs, and its accessibility and availability. It was evident that there is a dire need for academic support and that students benefited immensely by getting to university through ESP. In general, students believe that academic support should not be exclusively for first-year students and students who went to public schools. Support is for everyone and should be offered throughout the academic journey.

Research has shown dropout is perhaps the greatest problem facing institutions of higher education. As the number of students enrolling in tertiary education increases, so does the number of students who will be affected by dropout. Given the alarming number of dropouts in higher education institutions, it is pivotal that academic support is administered with urgency throughout all undergraduate programs, not just at the first-year level. It is also recommended that when students complete their first year of extended studies, the university can issue a certificate, endorsing the student for preparedness in higher education. We further recommend that other studies be taken from the students who did not come to the university through ESP because their school exit exams placed them in the mainstream.

\section{References}

Bangeni, A., \& Kapp, R. (Eds.) (2017). Negotiating learning and identity in higher education: Access, persistence, and retention. London: Bloomsbury.

Bitzer, E. M. (2003). Assessing students' changing perceptions of higher education. South African Journal of Higher Education 17(3), 164-177.

Bitzer, E.M (2009). Academic and social integration in three first-year groups: Holistic perspective. South African Journal of Higher Education 23(2), 225-245.

Boughey, C. (2010). Academic development for improved efficiency in the higher education and training system in South Africa. Johannesburg: Development Bank of Southern Africa.

Boughey, C. (2013). What Are We thinking of? A Critical Overview of Approaches to Developing Academic Literacy in South African Higher Education, Journal for Language Teaching, 47(2), 25-42.

Boughey, C., \& McKenna, S. (2016). Academic literacy and the decontextualised learner. Critical Studies in Teaching and Learning, 4(2), 1-9.

Council on Higher Education [CHE]. (2007). Higher Education Quality Committee (HEQC) institutional audits manual 2007. Pretoria: Council on Higher Education.

Council on Higher Education [CHE]. (2013). The higher education qualifications subframework. Pretoria: Council on Higher Education. 
Matabane, B. R. \& Matabane, M. E. Black Students' Experiences of Academic Support Programs during First Year at University: Case of Extended Studies

Council on Higher Education [CHE]. (2016). South African higher education reviewed: Two decades of democracy. Pretoria: Council on Higher Education.

Council on Higher Education [CHE]. (2018). VitalStats of public higher education 2016. Tshwane: Council on Higher Education.

Creswell, J. W. (2014). Research design. Los Angeles: SAGE Publications.

Department of Education [DoE]. (2001). National plan for higher education. Pretoria: Department of Education.

Department of Higher Education and Training [DHET]. (2012). Foundation provision in ministerially approved programmes. Pretoria: Department of Higher Education and Training.

Dison, L., \& Pinto, D. (2000). Developing materials for active learning. In S. Makoni (Ed.), Improving teaching and learning in higher education: A handbook for southern Africa (pp. 18-37). Johannesburg: Witwatersrand University Press.

Drewett, M. D. (1993). The integration of academic skills/support programmes into university department structures: A case study in the sociology of education. Unpublished Master Thesis, Rhodes University, Grahamstown.

Ellery, K. (2016). Conceptualising knowledge for access in the sciences: Academic development from a social realist perspective. Unpublished Doctoral Dissertation, Rhodes University, Grahamstown.

Jones, B., Coetzee, G., Bailey, T., \& Wickham, S. (2008). Factors that facilitate success for disadvantaged higher education students. Cape Town: Athlone.

Junio-Sabio, C. (2012). Importance of academic support services: An assessment by the students in Oman. International Journal of Information Technology and Business Management, 3(1), 14-23.

Khan, S. N. (2014). Qualitative research method: Grounded theory. International Journal of Business and Management, 9(11), 224-233.

Letseka, M., Cosser, M., Breier, M., \& Visser, M. (2009). Student retention and graduate destination: Higher education and labour market access and success. Cape Town: HSRC Press.

Louw, A. J. N. (2005). Staking van studie aan landbou-opleidingsinstellings in die wes-kaap: Waarskynlike oorsake en strategiee vir students-ondersteuning. Unpublished doctoral thesis, University of Stellenboch.

Lowe, H., \& Cook, A. (2003). Mind the gap: Are students prepared for higher education? Journal of Further and Higher education, 27(1), 53-76.

https://doi.org/10.1080/03098770305629

Maphosa, C. (2014). Towards a mainstream curriculum embedded student academic development programme in South African universities. International Journal of Educational Science, 6(1), 11-18.

Maton, K. (2014). Knowledge and knowers: Towards a realist sociology of education. New York, USA: Routledge.

Moerdyk, A.P. (2009). The principles and practice of psychological assessment. Pretoria: Van Schaik. 
Matabane, B. R. \& Matabane, M. E. Black Students' Experiences of Academic Support Programs during First Year at University: Case of Extended Studies

Mwangi, C. A. G., \& Yao, C. W. (2021). US higher education internationalization through an equity-driven lens: An analysis of concepts, history, and research. Higher Education: Handbook of Theory and Research, 36, 549-609.

Nel, C., Troskie-de Bruin, C., \& Bitzer, E. (2009). Students transition from school to possibilities for a pre-university intervention. South African Journal of Higher Education, 23(5), 974-995.

Ntakana, K.N. (2011). The effectiveness of student support programmes at a tertiary institution: A case study of Walter Sisulu University. KwaDlangezwa, Natal: University of Zululand.

Patimo, D. M., \& Lucero, M. B. A. (2021). Predictors of success in advance higher education: A case in Northwest Samar State University, Philippines. Research in Social Sciences and Technology, 6(1), 40-52.

Ramapela, S.S. (2012). Addressing the underpreparedness of students for post-secondary or higher education study by means of academic support programmes. IPEDR, 47(6), 2731

Rhodes University (2012). Rhodes University Funding Application Report, 2012. Department of Higher Education and Training: Application for approval of an extended curriculum programme. Unpublished report submitted to DoHET, Rhodes University, Grahamstown.

Rowley, J. (2014). Designing and using research questionnaires. Management Research Review, 37, 308-330.

Scott, I., Yeld, N., \& Hendry, J. (2007). A case for improving teaching and learning in South African higher education. Higher Education Monitor No. 6. Pretoria: Council on Higher Education.

Smith L. C. (2009). Measuring the success of an academic development programme: A statistical analysis. South African Journal of Higher Education, 23(5), 1009-1025.

Smolikevych, N. (2021). U.S. universities sociocultural and academic support for international students. Turkish Journal of Computer and Mathematics Education, 12(13), 37293744.

Spaull, N. (2013). South Africa's education crisis: The quality of education in South Africa 1994-2011. Johannesburg: Centre for Development and Enterprise.

Spaull, N. (2015). Schooling in South Africa: How low-quality education becomes a poverty trap. South African Child Gauge, 12, 34-41.

Strauss, L. C., \& Volkwein, J. F. (2004). Predictors of student commitment at two-year and four-year institutions. Journal of Higher Education, 75(2), 203-227.

Tanyanyiwa, P. (2014). A sociological analysis of the provision of extended studies as a means of addressing transformation at a historically white university. Unpublished Doctoral Thesis, Rhotes University, Grahamstown.

Tinto, V. (1993). Leaving college: Rethinking the causes and cures of student attrition. Chicago: University of Chicago Press.

Tinto, V. (1997). Classrooms as communities: Exploring the educational character of student persistence. Journal of Higher Education, 45(1), 89-125.

Tinto, V. (2003). Learning better together: The impact of learning communities on student success. Higher Education Monograph Series, 1(8), 1-8. 
Matabane, B. R. \& Matabane, M. E. Black Students' Experiences of Academic Support Programs during First Year at University: Case of Extended Studies

Tinto, V., \& Pusser, B. (2006). Moving from theory to action: Building a model of institutional action for student success. National Postsecondary Education Cooperative, 1, 51.

Valenzuela, J., Miranda-Ossandón, J., González-Sanzana, Á., \& Valenzuela, C. V. M. (2021). Academic support required by university students: evidence for higher education academic support policies. Formacion Universitaria, 14(3), 127-138

van Rijnsoever, F. J. (2017). Saturation: a simulation and guidelines for sample sizes in qualitative research. PLOS ONE, 12(7), e0181689.

van Schalkwyk S. C. (2007). Crossing discourse boundaries: Students' diverse realities when negotiating entry into knowledge communities. South African Journal of Higher Education, 21(7).

Warren, D. (1998). Educational intervention in higher education: From 'academic support' to 'academic development'. South African Journal of Higher Education, 12(3). https://hdl.handle.net/10520/AJA10113487_641

Weuffen, S., Fotinatos, N., \& Andrews, T. (2021). Evaluating sociocultural influences affecting participation and understanding of academic support services and programs (SSPS): Impacts on notions of attrition, retention, and success in higher education. Journal of College Student Retention: Research, Theory \& Practice, 23(1), 118-138.

Wong, Z. Y., \& Liem, G. A. D. (2021). Student engagement: Current state of the construct, conceptual refinement, and future research directions. Educational Psychology Review, 2021. https://doi.org/10.1007/s10648-021-09628-3

Yorke, M., \& Thomas, L. (2003). Improving the retention of students from lower socioeconomic groups. Journal of Higher Education Policy and Management, 25(1), 6374. https://doi.org/10.1080/13600800305737

\section{Appendixes}

\section{Appendix A: Copy of questionnaire administered to second year students}

1. Race: Black/White/ Indian/Colored

2. Gender: Male/ Female

3. Age group: 17-25, 26-34, 35-44

4. Kind of previous School: Private/ Public

5. How is your first-year experience? Good/ Bad/ satisfactory

6. Are you getting what you expected? Yes/ No

7. Do you feel like you coping academically? Yes/ No

8. Do you think the support given by ESP UNIT is enough?

9. Are you aware of various support available? Yes/ No

10. I know where I can go when I need help? Yes/ No

11. I need academic support: Yes/ No

12. My lecturers are a source of support: Yes/ No 
13. My tutors are a source of support: Yes/ No

14. Tutorials help me with learning: Yes/ No

15. I have used the kinds of support offered: Yes/ No

16. If your answer for 15 is Yes, how will you rate the support: Good/ Bad/ Moderate

17. If answer to 15 is No, why?

18. Since the beginning of year, have you felt like you need help in any of these?

$1=$ no, $2=$ a bit of help, $3=$ need help
a) Getting the literature
b) Taking notes in lectures
c) Writing assignments
d) Studying
e) Understanding lectures
f) Exam preparation and writing
g) Managing time
h) Other (specify)

19. IF yes to (18) could you rate its performance?

$1=$ did not help, 2-partly helped, $3=$ helped
a) Getting the literature
b) Taking notes in lectures
c) Writing assignments
d) Studying
e) Understanding lectures
f) Exam preparation and writing
g) Managing time
h) Other (specify)

20. Is there anything you with could change concerning the departments' support programmes?

21. If yes to question 20 please explain

22. The following are opinions which have been expressed about ASP.

Please indicate whether you:

1. Strongly agree, 2. Agree, 3. Disagree, 4. Strongly disagree

22.1. By not accounting for the weakness in South African schooling, the university is in effect blaming certain students for problems which are not of their own making 
Matabane, B. R. \& Matabane, M. E. Black Students' Experiences of Academic Support Programs during First Year at University: Case of Extended Studies

22.2. The university must maintain a high standard, and therefore is under no obligation to deal with problems which were caused by the school system

22.3. Students who experience difficulties with academic skills should deal with these in their own time

22.4. Because of the state of school education in South Africa, all students are underprepared for the demands of university, and therefore require some assistance with academic skills

22.5. Individual departments should build their teaching of relevant academic skills into their first-year course partly through lectures but particularly through the tutorial system, in a way which is not separate to course content.

22.6. course content and academic skills should be combined in a relevant way as far as possible

22.7. I think that I personally would benefit from a system which teaches academic skills along with course content

22.8. I would object to a system which teaches academic skills along with course content

22.9. Academic skills should only be taught in ASP, separately to departmental courses

22.10. ASP should try to change the university rather than change the student.

\section{Appendix B: Interview Guide}

1. How would you explain your second/ third year experience at university?

2. Are you part of support services offered by the university? (Department?)

- If yes which ones? Reason (s)?

- If no (Why not?)

3. Do you think the ERSU support you enough in your academics (skills required for the course?) please explain?

4. Is there any area that you would like the Department to improve or initiate concerning support given to students?

5. Would you say is the Department's responsibility to offer academic skills to students? (yes/no explain

6. What academic difficulties have you encountered during your second/third year experience?

7. Has the Department been of any use in dealing with the above mentioned?

8. Would you say you need academic support?

9. Have you been in a position where you do not know where to go when you need help with your academics?

10. Do you think tutorials aid with your studies?

11. Would you rather go to your tutor instead of your lecturer or anyone in the department?

12. Are you aware of the various support programs offered by the university? 